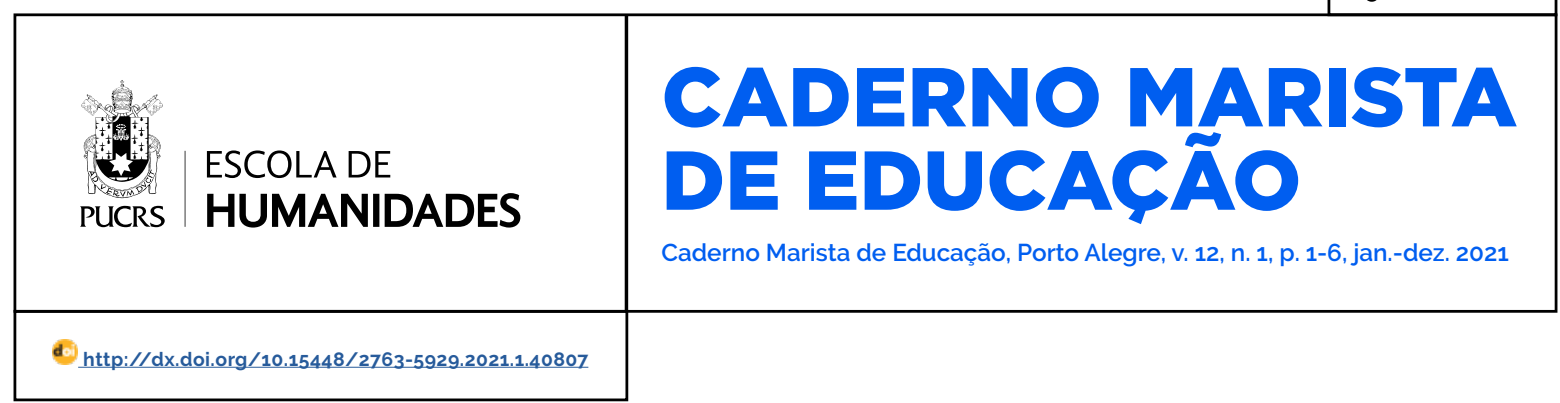

SEÇÃO: ARTIGOS

\title{
Utilização de um simulador computacional para o ensino do lançamento obliquo à luz da Teoria da Aprendizagem Significativa
}

Use of a computer simulator to teach the oblique launch in the light of the Theory of Meaningful Learning

\section{Wilson Leandro \\ Krummenauer ${ }^{1}$ \\ orcid.org/0000-0001-6651-4950 \\ wilson.leandro@maristas.org.br}

Recebido em: 24 abr. 2021 Aprovado em: 24 ago. 2021. Publicado em: 23 set. 2021.
Resumo: Neste artigo, relatamos uma experiência de ensino bem-sucedida na qual utilizamos um simulador computacional da plataforma Phet para demonstrar o lançamento oblíquo em uma turma do $2 .^{\circ}$ ano do ensino médio, no componente curricular de Física, em uma escola privada na cidade de Novo Hamburgo, RS. Utilizamos o simulador como atividade inicial de lançamento deste conteúdo nuclear a partir da seguinte situação-problema: para qual ângulo o alcance em um lançamento obliquo é máximo e para quais pares de ângulos, para uma mesma velocidade inicial de lançamento, o alcance é o mesmo? Os alunos, em duplas, variaram os seguintes parâmetros iniciais: velocidade inicial, ângulo de lançamento e objetos a serem lançados, com diferentes massas. A partir da variação destes fatores, os alunos puderam analisar a trajetória do movimento, os vetores velocidade e aceleração, bem como as componentes vetoriais, além de observar os fatores que interferem tanto na altura máxima quanto no alcance máximo horizontal. Ao final da atividade, aplicamos um questionário referente ao tópico abordado, tendo como resultado um aproveitamento próximo de $90 \%$ de respostas corretas.

Palavras-chave: Lançamento Obliquo. Ensino de Física. Aprendizagem significativa.

\begin{abstract}
In this article, we report a successful teaching experience in which we use a computer simulator from the Phet platform to demonstrate the oblique launch in a 2nd year class of High School, in the Physics curriculum component, in a private school in the city of Novo Hamburgo, RS. We use the simulator as the initial activity of launching this nuclear content from the following problem situation: for which angle the range in an oblique launch is maximum and for which pairs of angles, for the same initial launch speed, the range is the same? The students, in pairs, varied the following initial parameters: initial speed, launch angle and objects to be launched, with different masses. From the variation of these factors, the students were able to analyze the movement trajectory, the velocity and acceleration vectors, as well as the vector components, in addition to observing the factors that affect both the maximum height and the maximum horizontal reach. At the end of the activity, we applied a questionnaire referring to the topic covered, resulting in a utilization close to $90 \%$ of correct answers.
\end{abstract}

Keywords: Oblique Launch. Physics education. Meaningful learning.

\section{Introdução}

A proposta de ensino aqui apresentada foi desenvolvida com uma turma de 34 alunos do $2^{\circ}$ ano do ensino médio, no componente curricular de Física, no ano letivo de 2021, em uma escola privada localizada na cidade de Novo Hamburgo, RS. Com o objetivo de avaliar a influência 
dos parâmetros iniciais no lançamento obliquo, apresentamos aos alunos a seguinte situação-problema: para qual ângulo o alcance em um lançamento obliquo é máximo e para quais pares de ângulos, para uma mesma velocidade inicial de lançamento, o alcance é o mesmo? O lançamento obliquo é um dos conteúdos nucleares previstos para esse nivel de ensino, sendo o tipo de lançamento mais complexo estudado no ensino médio, pois além do movimento ser em duas dimensões envolve decomposição vetorial e é necessário o domínio básico da trigonometria.

Utilizamos como fundamentação teórica a teoria da aprendizagem significativa de David Ausubel e Joseph Novak. A aprendizagem significativa ocorre quando "a nova informação adquire significado por interação com conceitos ou proposições relevantes preexistentes na estrutura cognitiva" (MOREIRA; OSTERMANN, 1999, p. 62), sendo que essa relação deve ocorrer de maneira não literal e não arbitrária. Ausubel introduz a ideia de subsunçor, que é um conceito já existente na estrutura cognitiva do aluno, conceito esse que servirá de "ancoradouro" para a nova informação, adquirindo, desta maneira, significado para o aluno.

A aprendizagem significativa contrasta, fundamentalmente, com a aprendizagem mecânica, na medida em que, na primeira, a nova informação interage com algum "subsunçor", enquanto na segunda, não há nenhuma interação entre a nova informação e os conceitos ou proposições preexistentes na estrutura cognitiva do aluno. Um exemplo de aprendizagem mecânica é a memorização de um conteúdo sem qualquer fundamentação que lhe dê significado (KRUMMENAUER; COSTA, 2009).

Segundo Ausubel et al. (1980), existem algumas condições essenciais para a ocorrência da aprendizagem significativa: a) o professor deve averiguar os conhecimentos prévios dos alunos e ensinar a partir desses conhecimentos; b) outra condição fundamental para a ocorrência da aprendizagem significativa é que o material utilizado seja potencialmente significativo, isto é, esteja relacionado com a estrutura cognitiva do aluno de maneira não literal e não arbitrária; e c) independentemente de o material ser potencialmente significativo ou não, para ocorrer a aprendizagem significativa o aprendiz deve ter predisposição em aprender de forma significativa - o aluno não pode ter a intenção de memorizar ou decorar o material, tal postura levará à aprendizagem mecânica, isto é, sem nenhuma relação entre a nova informação e a estrutura cognitiva do aprendiz.

\section{Metodologia}

O simulador escolhido para o desenvolvimento da atividade foi elaborado pelo Projeto Simulações Interativas (PhET), da Universidade do Colorado. A plataforma possui atividades nas áreas da Física, da Química e da Biologia, e, também, é possivel filtrar a atividade escolhida de acordo com o tema da aula. O uso de simuladores nas aulas de Física tem se tornado uma excelente ferramenta no processo de ensino e aprendizagem, sobretudo no periodo da pandemia da COVID-19, período esse em que as aulas estão ocorrendo de forma remota e síncrona. As ferramentas computacionais permitem que o aluno simule experimentos que seriam extremamente complexos de serem demonstrados em um laboratório de ciências ou em outro espaço do ambiente escolar. Os simuladores permitem que o aluno formule e teste hipóteses, além de proporcionarem uma análise dos resultados obtidos. Nesse sentido, Valente (1995, p. 11) corrobora:

\footnotetext{
Esta modalidade de uso do computador na educação é muito útil para trabalho em grupo, principalmente os programas que envolvem decisões. Os diferentes grupos podem testar diferentes hipóteses, e assim, ter um contato mais "real" com os conceitos envolvidos no problema em estudo. Portanto, os potenciais educacionais desta modalidade de uso do computador são muito mais ambiciosos do que os dos programas tutoriais. Nos casos onde o programa permite um maior grau de intervenção do aluno no processo sendo simulado (por exemplo, definindo as leis de movimento dos objetos da simulação) o computador passa a ser usado mais como ferramenta do que como máquina de ensinar (VALENTE, 1995, p. 11),
} 
A Figura 1 representa a interface do simulador, nela o aluno pode alterar os seguintes parâmetros: velocidade inicial, ângulo de inclinação, altura inicial de lançamento, massa do objeto a ser arremessado, além de poder visualizar os vetores aceleração e velocidade, bem como suas componentes horizontal e vertical.

Figura 1 - Tela inicial do simulador

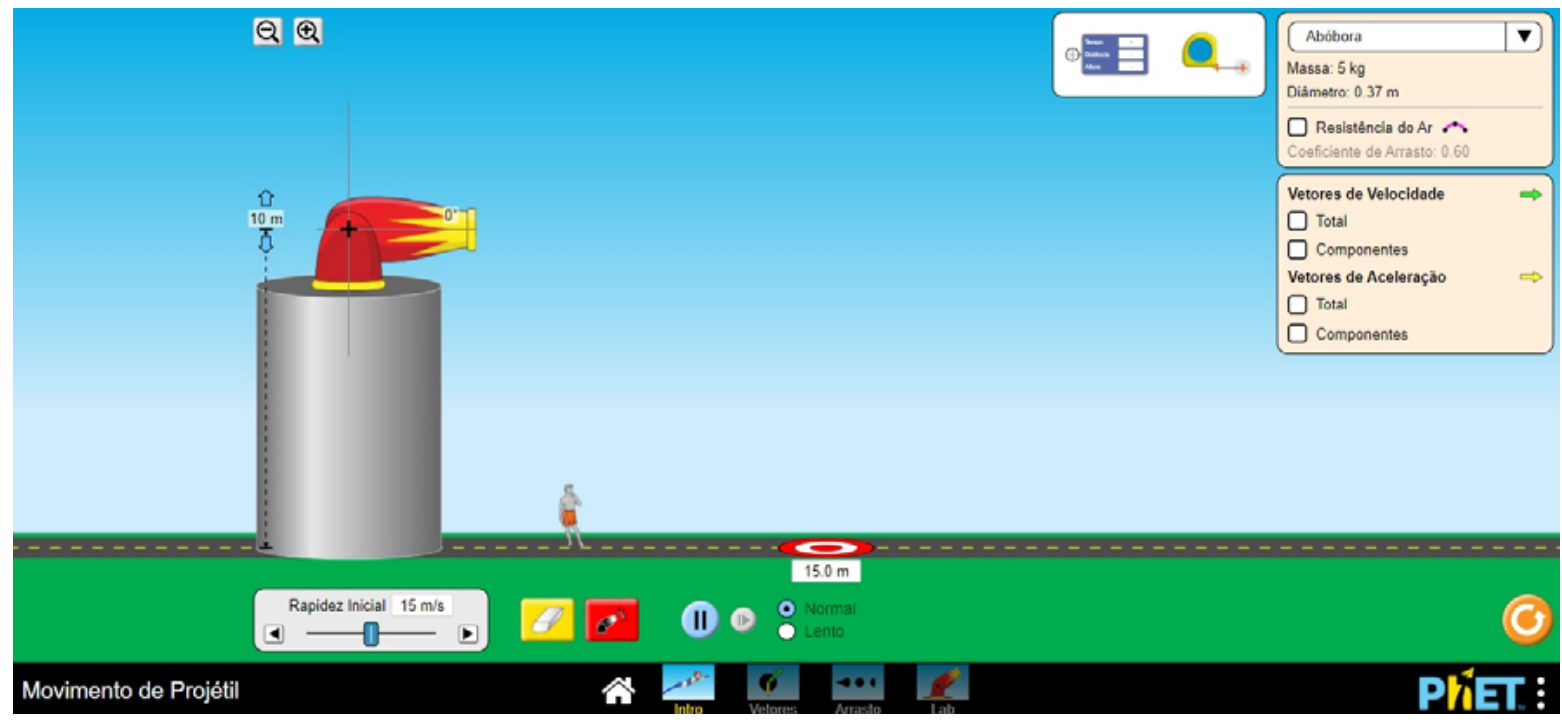

Fonte: Captura de tela realizada pelo autor em Projetctil Motion - Phet Interactive Simulations. ${ }^{2}$

Após formadas as duplas, ${ }^{3}$ os alunos acessaram a página do simulador e, a partir de suas escolhas pessoais, iniciaram o lançamento com diferentes ângulos de inclinação, diferentes velocidades iniciais e diferentes objetos a serem arremessados. Também foi solicitado aos alunos que variassem a altura inicial do lançamento, bem como ativassem o recurso da câmera lenta, desta forma foi possivel analisar com mais detalhe a trajetória do projétil. Os alunos também ativaram o recurso para visualizar os vetores aceleração e velocidade, bem como visualizar suas componentes vertical e horizontal. A Figura 2 apresenta o lançamento de um projétil com a representação do vetor velocidade e de suas componentes vertical e horizontal. Instigamos os alunos a verificarem para quais pares de ângulos o alcance horizontal era o mesmo e quais os fatores que interferem no tempo total de voo, na altura máxima e no alcance horizontal. 
Figura 2 - Lançamento de um projétil e a representação do vetor velocidade e de suas componentes vertical e horizontal

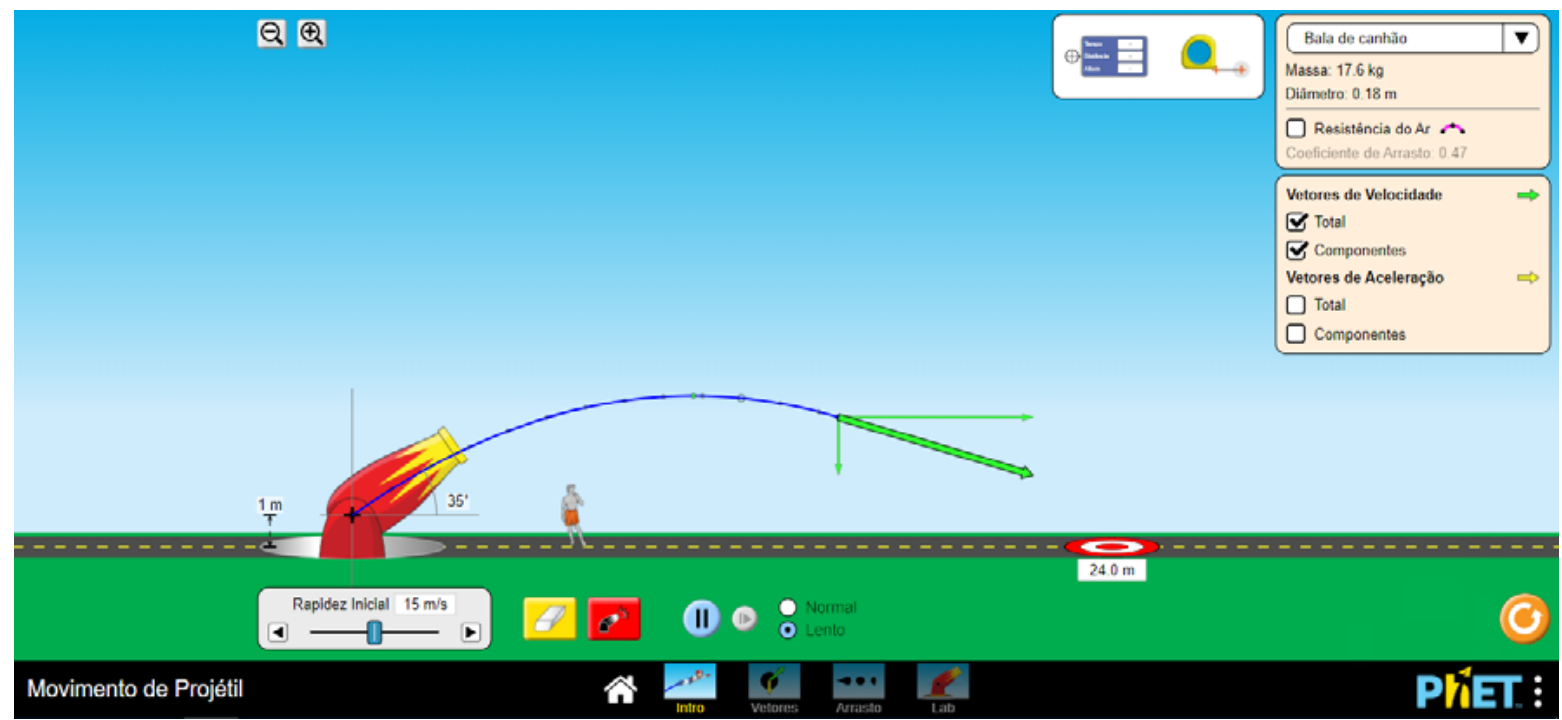

Fonte: Captura de tela realizada pelo autor em Projetctil Motion - Phet Interactive Simulations. ${ }^{4}$

\section{Resultados obtidos}

A atividade teve duração duas horas-aula e na aula seguinte à interação com o simulador os alunos responderam, em duplas, ao seguinte questionário5:

Após interagir com o simulador do lançamento obliquo, variando seus parâmetros iniciais, responda às perguntas a seguir:

1) Para que ângulo o alcance horizontal é máximo para uma mesma velocidade inicial?

2) Para quais pares de ângulos o alcance horizontal é o mesmo? Qual a sua conclusão a partir desta constatação?

3) O que você pode afirmar sobre as possiveis variações nas componentes horizontal e vertical da velocidade?

4) A aceleração do movimento é constante ou variável? Para onde aponta esta aceleração? Justifique.

5) Para uma mesma velocidade inicial, qual o fator que interfere na altura máxima atingida pelo projétil?

Na pergunta 1 do questionário objetivamos verificar se os alunos conseguiram identificar o ângulo correspondente ao alcance máximo para uma mesma velocidade inicial. Neste item as 17 duplas conseguiram identificar que o ângulo de $45^{\circ}$ corresponde ao máximo alcance na direção horizontal. Já na pergunta 2, sobre os pares de ângulos que apresentam o mesmo alcance para a mesma velocidade de lançamento, apesar de todas as duplas identificarem pares de ângulos corretos $\left(30^{\circ}\right.$ e $60^{\circ}, 25^{\circ}$ e $65^{\circ}, 40^{\circ}$ e $\left.50^{\circ}\right)$, duas duplas não conseguiram identificar a relação de que para ângulos complementares, isto é, aqueles cuja soma é $90^{\circ}$, fornecem o mesmo alcance horizontal para a mesma velocidade inicial.

Na pergunta 3, 16 duplas afirmam, de forma correta, que a componente vertical da velocidade varia no decorrer do tempo e que a componente horizontal da velocidade é constante, no entanto, uma das duplas foi além e afirmou que a componente vertical diminui seu módulo na subida e aumenta seu módulo na descida, invertendo seu sentido e tornando-se nula na altura máxima.

Sobre o questionamento referente à aceleração, 15 duplas afirmaram que o módulo dessa grandeza é constante e aponta verticalmente para baixo, sendo a aceleração gravitacional aquela

4 Disponivel em: https://phet.colorado.edu/pt_BR/simulation/projectile-motion. Acesso em: 20 abr. 2021.

O questionário foi elaborado pelo autor no mês de abril de 2021 e aplicado de forma on-line no ambiente virtual de aprendizagem Moodle no mês seguinte do respectivo ano 
presente no movimento. Duas duplas afirmaram que a aceleração é variável, diminuindo na subida e aumentando na descida.

Já na pergunta 5, todas as duplas afirmam que para uma mesma velocidade inicial, quanto maior o ângulo de inclinação, maior a altura máxima atingida pelo projétil.

\section{Considerações finais}

Pelos resultados apresentados no capítulo anterior, percebemos que todas as duplas conseguiram identificar o ângulo correspondente ao máximo alcance horizontal e identificar de forma correta pares de ângulos que produzem o mesmo alcance, representando 88\% da amostra. Já duas duplas, não conseguiram identificar que ângulos complementares geram o mesmo alcance. Apesar de apresentarem pares de ângulos corretos, esses alunos não conseguiram estabelecer uma relação entre os valores encontrados.

Todas as duplas obtiveram sucesso em identificar que o módulo do vetor velocidade na direção horizontal é constante e variável na direção vertical, além de que alguns alunos foram além e verificaram que a componente vertical é nula na altura máxima e que a velocidade resultante a cada instante é a soma vetorial das duas componentes.

Apenas $12 \%$ dos alunos afirmaram que a aceleração é variável, diminuindo seu módulo na subida e aumentando na descida. Esse percentual, correspondendo a duas duplas, possivelmente, confundiu o conceito aceleração com o conceito velocidade, pois esta segunda grandeza, na sua componente vertical, diminui seu módulo na subida e aumenta na descida. Para essas duplas, foi indicada uma lista de exercícios complementares e um texto de apoio diferenciando os conceitos de velocidade vetorial e aceleração.

Sobre a altura máxima, todas as duplas concluíram, de forma correta, que o ângulo de inclinação com a horizontal, para uma mesma velocidade inicial, é o fator determinante na altura máxima atingida.

Pelos resultados descritos anteriormente, percebemos a ocorrência da aprendizagem significativa, tanto em âmbito conceitual como no plano das variáveis envolvidas no fenômeno físico ilustrado no simulador. Segundo Moreira e Ostermann (1999), a ocorrência da aprendizagem significativa pode ser verificada através de uma situação física concreta diferente daquela apresentada pelo professor em sala de aula no momento da aula expositiva.

O simulador apresentado neste trabalho representa uma ferramenta didática extremamente potente no desenvolvimento de habilidades referentes ao lançamento de projéteis, permite que o aluno varie parâmetros, visualize a trajetória e os vetores aceleração e velocidade, além das componentes destes vetores. Através da variação desses parâmetros os alunos podem identificar os fatores que interferem no tempo de voo, no alcance horizontal e na altura máxima, além de permitir que extrapolem para outras situações a relação entre os conceitos trabalhados no simulador. A utilização de simulações computacionais no ensino de Física tem se mostrado um recurso importante para o desenvolvimento da aprendizagem significativa, não apenas o simulador descrito neste trabalho como em muitas outras situações físicas em que não é possivel o recurso do laboratório de ciências tradicional. A proposta aqui apresentada também pode ser desenvolvida de forma interdisciplinar com o componente curricular de matemática, sobretudo no estudo de

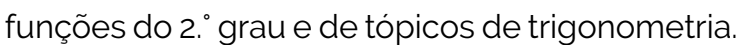

\section{Referências}

AUSUBEL, D. P.; NOVAK, J. D.; HANESIAN, H. Psicologia Educacional. Rio de Janeiro: Interamericana, 1980. 626 p.

KRUMMENAUER, W. L:; COSTA, S. S. C. Mapas conceituais como instrumentos de avaliação na Educação de Jovens e Adultos. Experiências em Ensino de Ciências (UFRGS), Porto Alegre, v. 4. p. 33-38, 2009.

MOREIRA, M. A.; OSTERMANN, F. Teorias construtivistas Porto Alegre: Gráfica do Instituto de Física - UFRGS, 1999. $63 \mathrm{p}$.

PROJECTIL MOTION. In: Phet Interactive Simulactions. University of Colorado Boulder. Disponivel em: https:// phet.colorado.edu/pt_BR/simulation/projectile-motion. Acesso em: 20 abr. 2021.

VALENTE, J. A. Diferentes usos do computador na educação. Campinas: Unicamp: 1995. 125 p. 


\section{Wilson Leandro Krummenauer}

Doutor em Educação em Ciências pela Universidade

Federal do Rio Grande do Sul (UFRGS), em Porto Alegre, RS, Brasil. Professor de Fisica do Colégio Marista Pio XII (CMPXII), em Novo Hamburgo, RS, Brasil.

\section{Endereço para correspondência}

Wilson Leandro Krummenauer

Colégio Marista Pio XII

Av. Nicolau Becker, 182

Vila Rosa, 93320-020

Novo Hamburgo, RS, Brasil

Os textos deste artigo foram revisados pela Poá Comunicação e submetidos para validação do autor antes da publicação. 